\title{
Mefenoxam Insensitivity and the Sexual Stage of Phytophthora capsici in Michigan Cucurbit Fields
}

\author{
K. H. Lamour and M. K. Hausbeck
}

Department of Botany and Plant Pathology, Michigan State University, East Lansing 48824-1312.

Accepted for publication 4 January 2000.

\begin{abstract}
Lamour, K. H., and Hausbeck, M. K. 2000. Mefenoxam insensitivity and the sexual stage of Phytophthora capsici in Michigan cucurbit fields. Phytopathology 90:396-400.

The potential for outcrossing, occurrence of oospores, and inheritance of mefenoxam sensitivity was assessed in naturally occurring populations of Phytophthora capsici. Between 1997 and 1998, 14 farms were sampled, with 473 isolates recovered from cucurbit hosts and 30 from bell pepper. The A1 and A2 compatibility types were recovered in a roughly 1:1 ratio in 8 of 14 farms with sample sizes larger than 15. In 1997, one isolate was designated as insensitive and four as sensitive to mefenoxam. In $1998,55 \%$ of the 498 isolates sampled were sensitive, 32\% were inter-

terization of mefenoxam sensitivity was conducted by crossing field isolates. Chi-square analysis of crosses between sensitive, intermediately sensitive, and insensitive isolates indicate that mefenoxam insensitivity segregated as an incompletely dominant trait unlinked to compatibility type $(P=0.05)$. Oospores were observed in diseased cucurbit fruit from four farms in 1998, and 223 oospore progeny were recovered from a single diseased cucumber. All six mefenoxam sensitivity-compatibility type combinations were present in these oospore progeny and within single fields. Based on these findings, we conclude that oospores likely play a role in the survival of $P$. capsici and that sexual recombination may significantly influence population structure.
\end{abstract} mediate, and $13 \%$ were fully insensitive to mefenoxam. In vitro charac-

Phytophthora capsici Leonian causes root, crown, and fruit rot on solanaceous and cucurbit hosts worldwide $(6,11,16)$. In Michigan, this pathogen causes serious damage annually to peppers, cucumbers, pumpkins, and squash. The asexual phase of the life cycle includes a mycelial thallus that produces extracellular enzymes capable of macerating host tissue (31), papillate sporangia borne on long (>20 $\mu \mathrm{m})$ caducous pedicels (29), and biflagellate, chemotactic, negatively geotropic zoospores that are liberated from sporangia under free-water conditions (26). The sexual phase occurs when isolates of opposite compatibility type (designated A1 and A2) are in close proximity, leading to the formation of thickwalled oospores. Oospores require an indeterminate time period ( 2 weeks to 3 months) for maturation, remain viable for extended periods of time (years), and are thought to be the primary survival structure (16). P. capsici is heterothallic; therefore, oospores have the potential to represent new gene combinations, in addition to their role as long-term dormant inoculum (11).

The principal methods of controlling $P$. capsici include cultural practices and the use of fungicides. Recommended cultural strategies are aimed at avoiding a build-up of inoculum by rotating to nonsusceptible hosts and planting in well-drained fields (25). Oomycetes, although morphologically similar to true fungi, are genetically and biochemically dissimilar (11) and are not susceptible to most broad-spectrum fungicides (8). For this reason, growers tend to rely on a limited number of fungicides. The phenylamide class of fungicides (PAF), specifically metalaxyl and the newest formulation, mefenoxam (Ridomil Gold EC), have been used on cucurbits in Michigan. Mefenoxam is the active enantiomer contained in the racemic fungicide metalaxyl (22). The mode of action of metalaxyl is postulated to be site specific, and it was not surprising when resistance surfaced in populations of susceptible plant pathogens after PAFs were introduced during the late 1970s (8).

Corresponding author: K. H. Lamour; E-mail address: lamourku@msu.edu

Publication no. P-2000-0217-03R

(C) 2000 The American Phytopathological Society
Additional keywords: phenylamide fungicide insensitivity.

Researchers investigating a range of obligate and hemibiotrophic oomycetes suggest that tolerance to PAFs is conditioned by a single locus having a major effect exhibiting incomplete dominance subject to modification by genes having minor effects $(2,5,7,12$, $28)$. Insensitivity to mefenoxam, which also conferred insensitivity to metalaxyl, recently has been reported from field populations of $P$. capsici on bell pepper (22).

The potential for outcrossing in epidemic populations of $P$. capsici has been reported based on the recovery of both the A1 and A2 mating types from soil samples and diseased plant material from single fields $(20,21,24)$. Typical amphyginous oospores have been reported in the United States on a single occasion from diseased bell-pepper tissue (21). In vitro analysis indicates that $P$. capsici oospore progeny are recombinant for pathogenicity to various hosts and mating type $(3,23)$.

This paper is a report on the initial phase of an investigation into the biology and structure of $P$. capsici populations in Michigan vegetable-production fields. The primary objective was to test the hypothesis that the sexual stage of $P$. capsici occurs in Michigan vegetable-production fields. In addition, we tested the hypothesis that mefenoxam resistance is inherited as a single dominant gene (19).

\section{MATERIALS AND METHODS}

Sampling strategy and pathogen isolation. Diseased plant material was collected in a haphazard fashion from fields with limited disease (e.g., a single focus of infection). In fields with widespread disease, the spatial distribution of isolates was documented, using permanent structures (e.g., telephone poles, houses, and barns) to construct field-specific grid patterns prior to sampling (Fig. 1). Grid block areas varied from $\approx 40 \mathrm{~m}^{2}$ to $12 \mathrm{~km}^{2}$ (Table 1). Infected plant material was selected at random from within blocks.

Diseased tissue was surface-sterilized with $70 \% \mathrm{EtOH}$ for $\approx 10 \mathrm{~s}$, and small pieces $(100 \times 15 \mathrm{~mm})$ of actively expanding lesions were plated on BARP (25 ppm of benomyl, $100 \mathrm{ppm}$ of ampicillin, $30 \mathrm{ppm}$ of rifampicin, and $100 \mathrm{ppm}$ of pentachloronitrobenzene)-amended 
UCV8 ( $840 \mathrm{ml}$ of distilled water, $163 \mathrm{ml}$ of unclarified V8 juice, $3 \mathrm{~g}$ of $\mathrm{CaCO}_{3}$, and $16 \mathrm{~g}$ of Bacto agar) plates (27). Plates were wrapped with Parafilm and incubated for 3 to 10 days in the dark at 23 to $25^{\circ} \mathrm{C}$. Once a colony had developed $(8 \mathrm{~cm}$ in diameter or larger), the Parafilm was removed from the petri dish, and the plates were incubated under lab lighting at 23 to $25^{\circ} \mathrm{C}$ for 2 to 3 days. This protocol stimulated ample sporangia production for zoospore release. Single-zoospore isolates were obtained by flooding the plates with sterile distilled water (SDW), placing plates in a $10^{\circ} \mathrm{C}$ refrigerator for $30 \mathrm{~min}$, incubating the plates at 23 to $25^{\circ} \mathrm{C}$ for $30 \mathrm{~min}$, placing 4 drops of the zoospore solution on water agar plates $(100 \times$ $15 \mathrm{~cm}$ ), and tilting the plates to get streaks of zoospores on the water agar surface. Plates were incubated for 45 to $90 \mathrm{~min}$ at 23 to $25^{\circ} \mathrm{C}$ and single, germinated zoospores were transferred to UCV8 with a dissecting microscope $(25 \times)$. Single-zoospore cultures were stored on UCV8 plates at $15^{\circ} \mathrm{C}$ and transferred monthly or bimonthly. In addition, two 7-mm plugs were placed in 20-ml screwtop vials with two sterilized hemp seeds and $10 \mathrm{ml}$ of SDW, incubated at 23 to $25^{\circ} \mathrm{C}$ for 2 weeks under laboratory lighting, and stored long term at $15^{\circ} \mathrm{C}(11)$.

Determination of compatibility type. Agar plugs from the edge of an expanding single-zoospore-derived colony were placed at the center of UCV8 plates $\approx 2 \mathrm{~cm}$ from ATCC (American Type Culture Collection, Manassas, VA) isolate 15427 (A1 compatibility type) and ATCC 15399 (A2 compatibility type), incubated at 23 to $25^{\circ} \mathrm{C}$ in the dark for 3 to 6 days, and compatibility type was determined. Thereafter, all compatibility type determinations were accomplished with the OP97 (A1) and SP98 (A2) field isolates.

In vitro response to mefenoxam. Agar plugs from the edge of actively expanding single-zoospore colonies were placed at the center of UCV8 plates $(100 \times 15 \mathrm{~cm})$ amended with 0 and $100 \mathrm{ppm}$ of mefenoxam (Ridomil Gold EC; $48 \%$ a.i., suspended in SDW, and

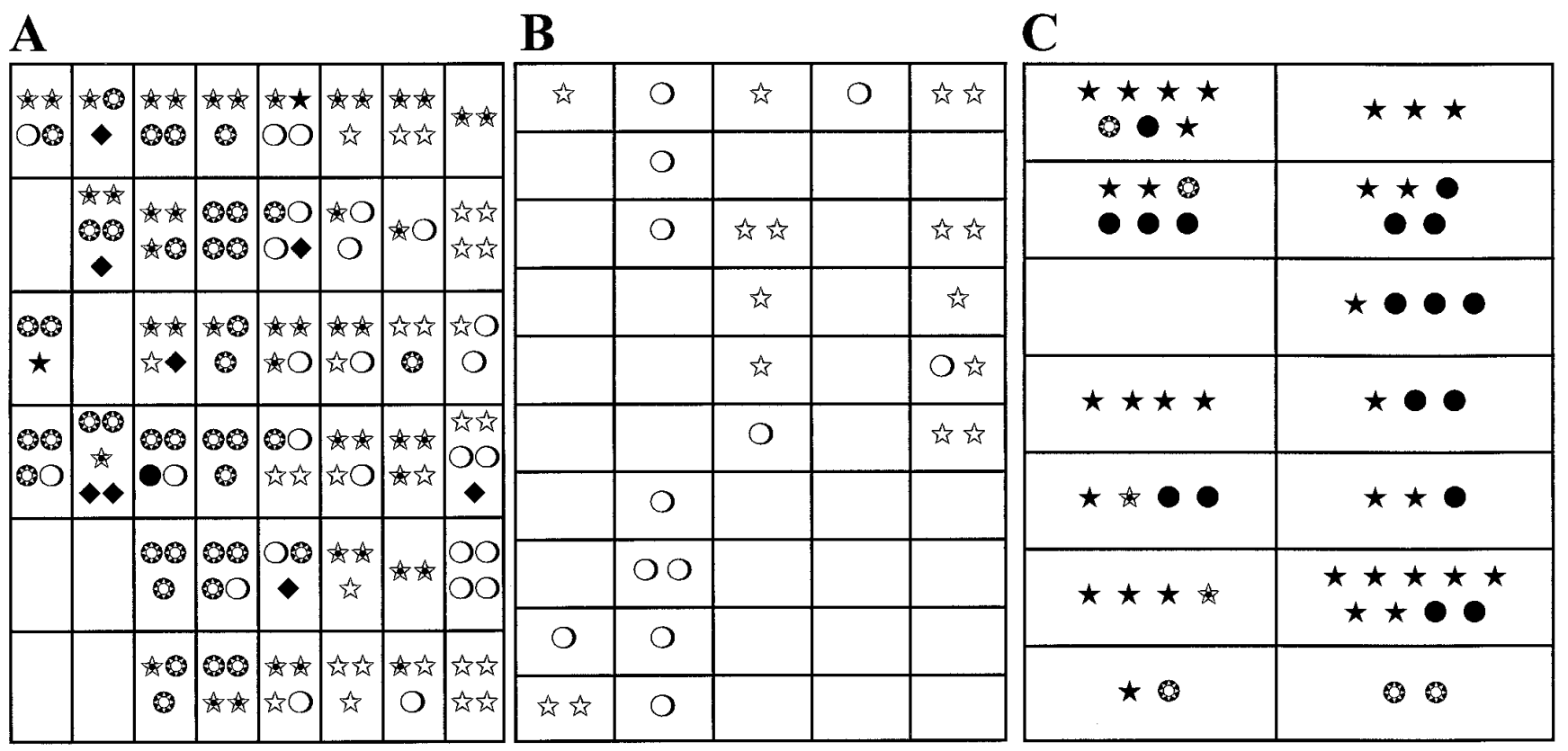

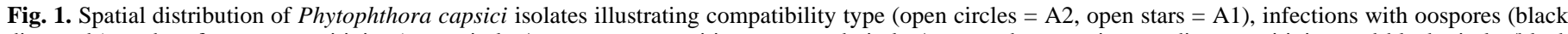

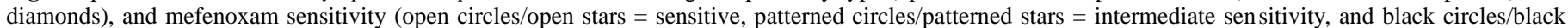


symbol represents a single isolate from a single infected plant or cucurbit fruit.

TABLE 1. Phytophthora capsici isolates described by collection in 1998

\begin{tabular}{|c|c|c|c|c|c|c|c|c|}
\hline \multirow[b]{2}{*}{ Location $^{\mathrm{a}}$} & \multirow[b]{2}{*}{$\operatorname{Host}^{\mathrm{b}}$} & \multirow[b]{2}{*}{ Sampling ${ }^{\mathrm{c}}$} & \multirow[b]{2}{*}{ No. of isolates } & \multicolumn{2}{|c|}{ Compatibility type $(\%)$} & \multicolumn{3}{|c|}{ Mefenoxam sensitivity $(\%)^{\mathrm{d}}$} \\
\hline & & & & A1 & A2 & $\mathrm{S}$ & IS & I \\
\hline SW1A & $\mathrm{S}, \mathrm{P}$ & $4 \mathrm{~km}^{2} /(1-5)^{\mathrm{e}}$ & 56 & 61 & 39 & 0 & 13 & 87 \\
\hline SW1B & $\mathrm{S}, \mathrm{C}$ & $40 \mathrm{~m}^{2} /(0-3)$ & 56 & 45 & 55 & 20 & 62 & 18 \\
\hline SW2 & $\mathrm{P}, \mathrm{M}, \mathrm{S}$ & $12 \mathrm{~km}^{2} /(0-6)$ & 16 & 56 & 44 & 81 & 19 & 0 \\
\hline SW3 & $\mathrm{P}$ & $\mathrm{H}$ & 6 & 17 & 83 & 80 & 20 & 0 \\
\hline SW4 & $\mathrm{C}$ & $\mathrm{H}$ & 5 & 80 & 20 & 20 & 60 & 20 \\
\hline SW5 & $\mathrm{P}$ & $\mathrm{H}$ & 4 & 75 & 25 & 40 & 60 & 0 \\
\hline $\mathrm{SC} 1 \mathrm{~A}$ & $\mathrm{C}$ & $1 \mathrm{~km}^{2} /(0-4)$ & 145 & 54 & 46 & 36 & 62 & 2 \\
\hline $\mathrm{SC} 1 \mathrm{~B}$ & $\mathrm{C}$ & $6 \mathrm{~km}^{2} /(0-6)$ & 82 & 46 & 54 & 44 & 53 & 3 \\
\hline $\mathrm{SC} 2$ & $\mathrm{C}$ & $\mathrm{H}$ & 20 & 90 & 10 & 5 & 80 & 15 \\
\hline $\mathrm{C} 1$ & $\mathrm{P}, \mathrm{S}$ & $\mathrm{H}$ & 16 & 19 & 81 & 88 & 12 & 0 \\
\hline NW1 & $\mathrm{BP}$ & $4 \mathrm{~km}^{2} /(0-5)^{\mathrm{e}}$ & 30 & 63 & 37 & 93 & 3 & 4 \\
\hline NW2A & $\mathrm{S}$ & $\mathrm{H}$ & 29 & 52 & 48 & 90 & 7 & 3 \\
\hline NW2B & $\mathrm{C}, \mathrm{S}$ & $40 \mathrm{~m}^{2} /(0-3)$ & 28 & 57 & 43 & 100 & 0 & 0 \\
\hline NW3 & $\mathrm{S}$ & $\mathrm{H}$ & 5 & 20 & 80 & 80 & 20 & 0 \\
\hline Total & $\ldots$ & $\ldots$ & 498 & 52 & 48 & 55 & 32 & 13 \\
\hline
\end{tabular}

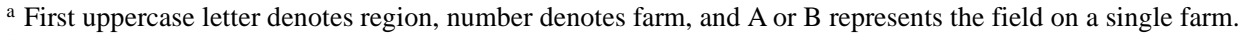

b $\mathrm{P}=$ pumpkin, $\mathrm{C}=$ cucumber, $\mathrm{M}=$ melon, $\mathrm{S}=$ squash, and $\mathrm{BP}=$ bell pepper.

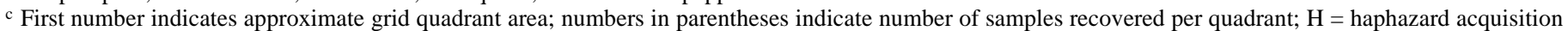
of diseased material from fields.

d $\mathrm{S}=$ sensitive, IS = intermediate sensitivity, and I = insensitive.

e Refers to samples collected from fungicide trial plots with mefenoxam as one of the treatments. 
added to UCV8 cooled to $49^{\circ} \mathrm{C}$ ). Inoculated plates were incubated at 23 to $25^{\circ} \mathrm{C}$ for 3 days, and colony diameters were measured. Percent growth of an isolate on amended media was calculated by subtracting the inoculation plug diameter $(7 \mathrm{~mm})$ from the diameter of each colony and dividing the average diameter of the amended plates by the average diameter of the unamended control plates (9). All tests were conducted at least twice. Field isolates were assigned putative mefenoxam sensitivities based on the percent growth of the control, as determined above. An isolate was scored as sensitive if growth at 100 ppm was less than $30 \%$ of the control, intermediately sensitive if growth was between 30 and $90 \%$ of the control, and insensitive if growth was greater than $90 \%$ of the control. Preliminary cutoffs were determined by visual as-

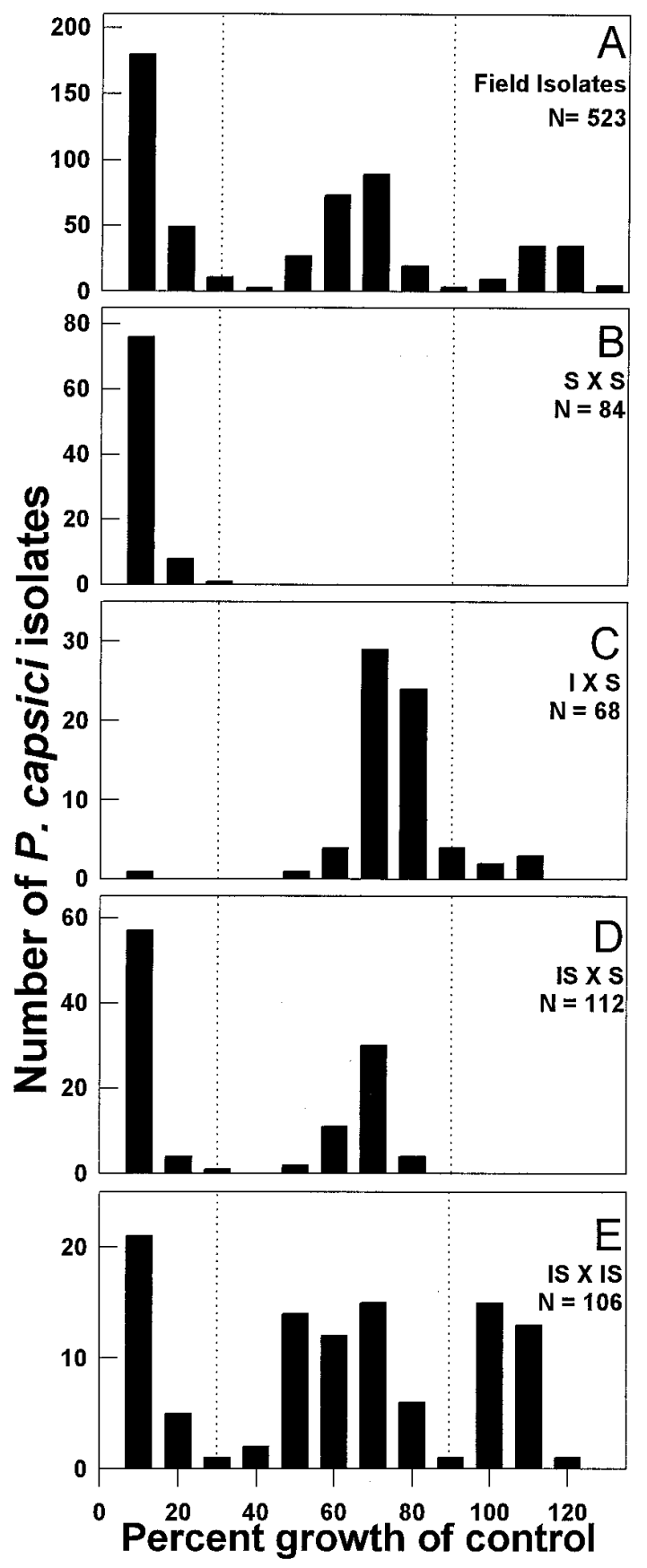

Fig. 2. Frequency of mefenoxam sensitivity in Phytophthora capsici for A, 1997 to 1998 field isolates and in vitro progeny from crosses: B, SLCC-6B $\times$ OP97; C, SSB98 $\times$ OP97; D, SFF-3 $\times$ OP97; and E, $244 \times 216$. S $=$ sensitive, $<30 \%$ growth of control (GC); IS = intermediate, 30 to $90 \%$ GC; I = insensitive, $>90 \% \mathrm{GC}$; and $\mathrm{N}=$ number of isolates. sessment of the frequency of mefenoxam sensitivity in field isolates (Fig. 2A).

Segregation analysis. The validity of these mefenoxam-sensitivity assignments was tested by crossing isolates representative of the three groups from within and between diverse geographic locations and comparing the ratios of progeny phenotypes to those expected under Mendelian inheritance, using chi-square analysis. Isolate OP97 (A1, sensitive, farm NW2B) was crossed with isolates SSB98 (A2, insensitive, farm SW1A), SLCC-6B (A2, sensitive, farm SC1B), and SFF-3 (A2, intermediate sensitivity, farm SC1A) and isolate 216 (A1, intermediate sensitivity, farm SC1A ) was crossed with 244 (A2, intermediate sensitivity, farm SC1A). Crossing was performed as described in the compatibility type screen. Plates were incubated at 23 to $25^{\circ} \mathrm{C}$ in the dark for 3 to 4 months (15), and the surface of a $1-\mathrm{cm}^{2}$ area was scraped from the zone containing oospores between inoculation plugs. Scrapings were placed in $10 \mathrm{ml}$ of SDW and homogenized in a mixer (Ivan Sorvall Inc., Norwalk, CT) on the highest setting for $3 \mathrm{~min}$. Novozyme $(5 \mathrm{mg} / \mathrm{ml}$; Sigma-Aldrich Chemical Co., St. Louis) was added to the homogenate, and the solutions were incubated on a shaker (200 rpm) overnight (18 to $24 \mathrm{~h}$ ). Solutions were diluted 1:10 with SDW and incubated in petri dishes $(15 \times 100 \mathrm{~cm})$ under fluorescent lighting (1). After $\approx 24 \mathrm{~h}$, germinated oospores were retrieved from the suspensions with a suction device constructed from a Pasteur pipette (11). Germinated oospores are characterized by dissolution of the electron-dense thick wall and the presence of one too many germ tubes with or without terminal sporangia. Individual oospores were transferred to water agar plates, and after 1 to 2 days, single hyphal tips were transferred to UCV8 plates. Single-oospore hyphaltip progeny were screened for mating type and sensitivity to mefenoxam as described above.

Naturally occurring oospores. Selected infected fruit were observed for the presence or absence of oospores. Slides were prepared by excising a thin slice of suspect tissue, staining with crystal violet (300 ppm), and inspecting for typical amphigynous oospores under a light microscope (Laborlux S, Leitz, Wetzlar, Germany). Diseased plant material containing amphigynous oospores typical for $P$. capsici was surface-sterilized with $70 \% \mathrm{EtOH}$ for $\approx 10 \mathrm{~s}$, and a 1-cm section was embedded in BARP-UCV8 media. Plates were incubated for 3 to 4 months in the dark. After incubation, the initial diseased plant material was removed and subjected to the germination procedure described above.

\section{RESULTS}

Mefenoxam sensitivity and compatibility type among isolates. Single isolates of $P$. capsici were recovered from five farms in 1997: one from bell pepper (A2, resistant) and four from cucurbit hosts (A1, sensitive). In 1998, 498 isolates were obtained from 11 farms: 468 from cucurbit hosts and 30 from bell pepper (Table 1). In 1998, 258 A1 and 240 A2 compatibility types were recovered; both compatibility types were found in every field sampled. Of 10 fields with sample sizes larger than 15, 8 had an approximate 1:1 ratio of A1 and A2 compatibility types (Table 1). When fields were sampled on a grid, both A1 and A2 compatibility types were located within and among geographically diverse quadrants (Fig. 1).

TABLE 2. Phenotypic diversity of 223 Phytophthora capsici oospores isolated from a single naturally infected cucumber

\begin{tabular}{lcccc}
\hline & \multicolumn{3}{c}{ Mefenoxam sensitivity $(\%)^{\mathrm{a}}$} & \\
\cline { 2 - 4 } Compatibility type & $\mathrm{S}$ & $\mathrm{IS}$ & $\mathrm{I}$ & Total \\
\hline A1 & $16(35)$ & $23(52)$ & $10(23)$ & $49(110)$ \\
A2 & $19(41)$ & $22(49)$ & $10(23)$ & $51(113)$ \\
Total & $35(76)$ & $45(101)$ & $20(46)$ & $\ldots$ \\
\hline
\end{tabular}

a $\mathrm{S}=$ sensitive, IS = intermediate sensitivity, and $\mathrm{I}=$ insensitive. Number of isolates is given in parentheses. 
In 1997, one isolate was designated as insensitive and four as sensitive to mefenoxam. In 1998, 55\% (274) of the isolates were sensitive, $32 \%$ (161) were intermediate, and 13\% (63) were fully insensitive to mefenoxam (Table 1). Of the 14 farms sampled during 1997 and 1998, 43\% had fully insensitive isolates and 79\% had isolates of intermediate sensitivity (Table 1). Insensitive isolates were not recovered from six of the farms sampled. With one exception, fully sensitive isolates were recovered from all farms sampled (Fig. 2A).

Three fields with sample sizes larger than 15 were of particular interest because they represent predominantly sensitive, intermediately sensitive, or fully insensitive populations of $P$. capsici (Fig. 1). Within field SW1A, in the southwestern region, 87\% (56) of the isolates were fully insensitive to mefenoxam, with no sensitive isolates recovered (Table 1). Both A1 and A2 isolates were recovered from 9 of 13 quadrants sampled (Fig. 1C). In contrast, in field SW1B on the same farm, the majority $(62 \%)$ of the isolates (56) had intermediate sensitivity, and $20 \%$ were fully sensitive (Table 1). When four other fields in southwestern Michigan were sampled in a limited manner (i.e., fewer than 16 samples), an insensitive isolate was recovered in one field (Table 1). In southcentral Michigan, intermediately sensitive strains dominated in all fields (Table 1). Isolates (145) collected on a single day from a field of pickling cucumbers in south-central Michigan represented all six combinations of mefenoxam sensitivity and compatibility type, with $17 \%$ sensitive A2, $20 \%$ sensitive A1, $28 \%$ intermediately sensitive A2, 32\% intermediately sensitive A1, $1 \%$ insensitive A2, and $2 \%$ insensitive A1 isolates (Fig. 1A). In northwestern Michigan, fully sensitive strains dominated all fields sampled (Table 1). In one of the seven grids where two samples were collected, both A1 and A2 compatibility types were present (Fig. 1B).

Oospores in the field. In 1998, typical amphigynous oospores were observed in diseased cucurbit fruit collected from multiple locations on farms in south-central (cucumber, Fig. 1A) and southwestern Michigan (butternut squash) and single locations on additional farms (pumpkin, cucumber) in these regions. Single-zoospore isolates were cultured from each of the infected fruit. A total of 223 single-oospore progeny was recovered from a single cucumber from the southwestern region and identified as $P$. capsici based on the presence of typical papillate, caducous sporangia borne on long $(>20 \mu \mathrm{m})$ pedicels (11). These progeny exhibited diversity for mating type and mefenoxam sensitivity (Table 2 ).

In vitro segregation analysis of mefenoxam insensitivity and compatibility type. Each of the in vitro crosses resulted in greater than $60 \%$ germination of oospores. A cross between sensitive isolates originating from the northern (OP97) and south-central (SLCC$6 \mathrm{~B}$ ) regions of Michigan (Fig. 2B, Table 3 ) resulted in $48 \mathrm{~A} 1$ and 37 A2 sensitive progeny (Fig. 2B). Crossing OP97 (sensitive) with an insensitive isolate (SSB98) from the southwestern region of
Michigan resulted in $33 \mathrm{Al}$ and $35 \mathrm{~A} 2$ isolates, with $91 \%$ of the progeny designated as intermediately sensitive, $2 \%$ as sensitive, and $7 \%$ as insensitive (Fig. 2C). Isolate OP97 (sensitive) crossed with an intermediately sensitive isolate (SFF3) from southwestern Michigan resulted in $51 \mathrm{~A} 1$ and $61 \mathrm{~A} 2$ isolates, with $53 \%$ of the $\mathrm{A} 1$ and $58 \%$ of the A2 designated as sensitive, and $47 \%$ of the A1 and $42 \%$ of the A2 designated as intermediately sensitive (Fig. 2D). A cross between two intermediately sensitive isolates $(244 \times 216)$ from the same field in south-central Michigan resulted in $10 \%$ A1 and $16 \%$ A2 sensitive isolates, $20 \% \mathrm{~A} 1$ and $28 \%$ A2 intermediately sensitive isolates, and $11 \% \mathrm{~A} 1$ and $15 \% \mathrm{~A} 2$ insensitive isolates (Fig. 2E). None of the progeny sets deviated from the expected ratios for mefenoxam insensitivity segregating as an incompletely dominant trait or compatibility type segregating in a $1: 1$ ratio $(P=0.05)$. Chi-square tests for linkage between mefenoxam insensitivity and compatibility type in the progeny of the in vitro sexual crosses SFF3 $\times$ OP97 and $244 \times 216$ indicate these phenotypes are unlinked $(P=0.05)$ (Table 3$)$.

\section{DISCUSSION}

During the past 10 years, Michigan has experienced a steady increase in the incidence of root, fruit, and crown rot on cucurbits caused by $P$. capsici. Rotation to nonsusceptible hosts for up to 4 years, in conjunction with cultural and chemical control strategies, have not provided economic control. The polycyclic nature of asexual reproduction and the role of environmental factors such as free water in disease development are well understood (4), but the role of the sexual stage in natural populations has not been investigated. Due to the survival capabilities of the oospore and the genetic implications inherent in outcrossing and recombination, sexual reproduction has the potential to significantly affect naturally occurring populations $(10,14)$.

A hallmark of sexually active populations is the presence of both compatibility types in a $1: 1$ ratio $(14,17)$. This criterion was met in many of the fields sampled during 1998. Sample sets that reflect the spatial distribution of isolates indicate A1 and A2 compatibility types occur throughout epidemic populations.

Once the sexual stage of heterothallic species of Phytophthora has been stimulated, there is the potential for selfing as well as outcrossing. This may explain the fully sensitive and fully insensitive progeny recovered from our SSB98 (insensitive) $\times$ OP97 (sensitive) cross. Our initial assignment of three mefenoxam sensitivity classes was confirmed by $\chi^{2}$ analysis of progeny phenotypes compared to those expected under Mendelian segregation for a single dominant gene. Our in vitro findings that mefenoxam sensitivity in $P$. capsici is conditioned by a single, incompletely dominant gene and that this phenotype is unlinked to compatibility type, provide useful information for assessing population structure. Although the frequency

TABLE 3. Chi-square analysis of Phytophthora capsici crosses for segregation and linkage of compatibility type (CT) and mefenoxam sensitivity (MS) ${ }^{\mathrm{a}}$

\begin{tabular}{|c|c|c|c|c|c|c|c|}
\hline Cross & Parent isolate & Isolate origin ${ }^{b}$ & $\mathrm{CT}$ & MS & $\mathrm{CT}^{\mathrm{b}}$ & MS & CT and MS linkage \\
\hline \multirow[t]{2}{*}{1} & SLCC-6B & $\mathrm{SC} 1 \mathrm{~B}$ & A2 & $\mathrm{S}$ & $1: 1^{* c}$ & $\ldots$ & $\ldots$ \\
\hline & OP97 & NW2B & $\mathrm{A} 1$ & S & $48: 37^{d}$ & $\ldots$ & $\ldots$ \\
\hline 2 & SSB98 & SW1A & A2 & I & $1: 1^{*}$ & $\ldots$ & $\ldots$ \\
\hline \multirow[t]{2}{*}{3} & SFF3 & SC1A & A2 & IS & $1: 1^{*}$ & $1: 1^{*}$ & $1: 1: 1: 1^{*}$ \\
\hline & OP97 & NW2B & A1 & $\mathrm{S}$ & $51: 61$ & $63: 49^{\mathrm{e}}$ & $27: 35: 25: 25^{\mathrm{f}}$ \\
\hline \multirow[t]{2}{*}{4} & 244 & SC1A & A2 & IS & $1: 1^{*}$ & $1: 2: 1^{*}$ & $1: 1: 2: 2: 1: 1^{*}$ \\
\hline & 216 & SC1A & $\mathrm{A} 1$ & IS & $43: 63$ & $27: 51: 28^{\mathrm{g}}$ & $10: 17: 21: 30: 12: 16^{\mathrm{h}}$ \\
\hline
\end{tabular}

${ }^{a} \mathrm{~S}=$ sensitive, $\mathrm{IS}=$ intermediate sensitivity, and $\mathrm{I}=$ insensitive.

${ }^{\mathrm{b}}$ First uppercase letter denotes region, number denotes farm, and A or B indicates field.

${ }^{c}$ Expected Mendelian ratio; * indicates chi-square value not significant at $P=0.05$.

d A1:A2 progeny.

e S:IS progeny.

f S/A1:S/A2:IS/A1:IS/A2 progeny.

g S:IS:I progeny.

${ }^{\text {h }}$ S/A1:S/A2:IS/A1:IS/A2:I/A1:I/A2 progeny. 
of mefenoxam sensitivity is influenced by the method, frequency, and rate of fungicide application and becomes less informative in situations where populations are either fully resistant or fully sensitive, it does provide useful information in fields with a mixture of phenotypes. The probability of finding all six mefenoxam sensitivity-compatibility type combinations in the same field in the absence of sex is unlikely $(13,18)$.

The recovery and germination of typical amphigynous oospores from naturally infected cucurbit fruit provides direct evidence for sexual reproduction. It is clear that these progeny have the potential to serve as a diverse inoculum representing every combination of compatibility type and mefenoxam sensitivity.

Based on the composite picture presented by these various lines of investigation, we conclude that sexual reproduction plays an active role in the survival of $P$. capsici in Michigan and may play a significant role in shaping population structure. Overwintering and long-term viability of oospores represents an obvious advantage gained by sexually active populations of $P$. capsici, but there may be an additional gain when insensitivity to mefenoxam is considered. A viable strategy for recovering the effectiveness of a fungicidal management tool in the advent of widespread resistance is to stop using the fungicide and allow populations to shift back to sensitivity. This strategy is based on the phenomenon of a fitness cost for resistance and hinges on the idea that resistant isolates are less fit and will be unable to compete with sensitive isolates after the removal of the selective pressure (30). If sexual reproduction has played a role in the overwintering and survival of $P$. capsici, concomitant with PAF usage, it is possible that outcrossing and recombination in the population may generate a genotypically diverse array of resistant isolates. In this scenario, the negative impact of genetic hitchhiking that may occur when resistance occurs within a single clone would be avoided, and it would be less likely that resistant isolates, in total, harbor fitness disadvantages linked to mefenoxam insensitivity. Even if the wild-type sensitive allele is not pushed to complete extinction, there may be no reason for sensitive isolates to increase disproportionally when the selection pressure is removed.

The findings reported in this paper may explain why rotational strategies ( $>2$ years) to a nonsusceptible host have not provided control and may give some insight into the failure of mefenoxam in controlling blight caused by $P$. capsici on cucurbits in Michigan.

\section{ACKNOWLEDGMENTS}

This work was funded by the Michigan Agricultural Experiment Station, Michigan State University Extension, Michigan Department of Agriculture, Michigan Farm Bureau (GREEEN cooperative), Pickle and Pepper Research Committee, Pickle Packers International, Inc., and the Pickle Seed Research Fund, Pickle Packers International. We thank A. M. Jarosz for critical comments on the manuscript and valuable criticism during this project, E. A. Webster for supervision of lab procedures, and M. Bour for competent lab assistance.

\section{LITERATURE CITED}

1. Berg, L. A., and Gallegly, M. E. 1966. Effect of light on oospore germination of species of Phytophthora. (Abstr.) Phytopathology 56:583.

2. Bhat, R. G., McBlain, B. A., and Schmitthenner, A. F. 1993. The inheritance of resistance to metalaxyl and to fluorophenylalanine in matings of homothallic Phytophthora sojae. Mycol. Res. 97:865-870.

3. Bowers, J. H., and Mitchell, D. J. 1991. Relationship between inoculum level of Phytophthora capsici and mortality of pepper. Phytopathology $81: 178-184$.

4. Cafe Filho, A. C., Duniway, J. M., and Davis, R. M. 1995. Effects of the frequency of furrow irrigation on root and fruit rots of squash caused by
Phytophthora capsici. Plant Dis. 79:44-48.

5. Chang, T. T., and Ko, W. H. 1990. Resistance to fungicides and antibiotics in Phytophthora parasitica: Genetic nature and use in hybrid determination. Phytopathology 80:1414-1421.

6. Crossan, D. F., Haasis, F. A., and Ellis, D. E. 1954. Phytophthora blight of summer squash. Plant Dis. Rep. 38:557-559.

7. Crute, I. R., and Harrison, J. M. 1988. Studies on the inheritance of resistance to metalaxyl in Bremia lactucae and on the stability and fitness of field isolates. Plant Pathol. 37:231-250.

8. Davidse L. C., van den Berg-Velthuis, G. C. M., Mantel, B. C., and Jespers, A. B. K. 1991. Phenylamides and Phytophthora. Pages 349-360 in: Phytophthora. J. A. Lucas, R. C. Shattock, D. S. Shaw, and L. R. Cooke, eds. British Mycological Society, Cambridge.

9. Deahl, K. L., DeMuth, S. P., Sinden, S. L., and Rivera-Pena, A. 1995. Identification of mating types and metalaxyl resistance in North American populations of Phytophthora infestans. Am. Potato J. 72:35-49.

10. Drenth, A., Janssen, E. M., and Govers, F. 1995. Formation and survival of oospores of Phytophthora infestans under natural conditions. Plant Pathol. 44:86-94.

11. Erwin, D. C., and Ribeiro, O. K. 1996. Phytophthora Diseases Worldwide. The American Phytopathological Society, St. Paul, MN.

12. Fabritius, A., Shattock, R. C., and Judelson, H. S. 1997. Genetic analysis of metalaxyl insensitivity loci in Phytophthora infestans using linked DNA markers. Phytopathology 87:1034-1040.

13. Georgopoulos, S. G. 1988. Genetics and population dynamics. Pages 1213 in: Fungicide Resistance in North America. C. J. Delp, ed. The American Phytopathological Society, St. Paul, MN.

14. Goodwin, S. B. 1997. The population genetics of Phytophthora. Phytopathology 87:462-473.

15. Harnish, W. N. 1965. Effect of light on production of oospores and sporangia in species of Phytophthora. Mycologia 57:85-90.

16. Hwang, B. K., and Kim, C. H. 1995. Phytophthora blight of pepper and its control in Korea. Plant Dis. 79:221-227.

17. McDonald, B. A., and McDermott, J. M. 1993. Population genetics of plant pathogenic fungi. BioScience 43:311-319.

18. Milgroom, M. G. 1995. Analysis of population structure in fungal plant pathogens. Pages 203-219 in: Biotechnology: Interdisciplinary Bridges to Improved Sorghum and Millet Crops. J. F. Leslie and R. A. Fredriksen, eds. Iowa State University Press, Ames.

19. Milgroom, M. G. 1996. Recombination and the multilocus structure of fungal populations. Annu. Rev. Phytopathol. 34:457-477.

20. Miller, S. A., Bhat, R. G., and Schmitthenner, A. F. 1994. Detection of Phytophthora capsici in pepper and cucurbit crops in Ohio with two commercial immunoassay kits. Plant Dis. 78:1042-1046.

21. Papavizas, G. C., Bowers, J. H., and Johnston, S. A. 1981. Selective isolation of Phytophthora capsici from soils. Phytopathology 71:129-133.

22. Parra, G., and Ristaino, J. B. 1998. Insensitivity to Ridomil Gold (mefenoxam) found among field isolates of Phytophthora capsici causing Phytophthora blight on bell pepper in North Carolina and New Jersey. Plant Dis. 82:711.

23. Polach, F. J., and Webster, R. K. 1972. Identification of strains and inheritance of pathogenicity in Phytophthora capsici. Phytopathology 62:20-26.

24. Ristaino, J. B. 1990. Intraspecific variation among isolates of Phytophthora capsici from pepper and cucurbit fields in North Carolina. Phytopathology 80:1253-1259.

25. Ristaino, J. B., Hord, M. J., and Gumpertz, M. L. 1992. Population densities of Phytophthora capsici in field soils in relation to drip irrigation, rainfall, and disease incidence. Plant Dis. 76:1017-1024.

26. Schlub, R. L. 1983. Epidemiology of Phytophthora capsici on bell pepper. J. Agric. Sci. 100:7-11.

27. Schmitthenner, A. F., and Bhat, R. G. 1994. Useful Methods for Studying Phytophthora in the Laboratory. OARDC, Wooster, OH.

28. Shattock, R. C. 1988. Studies on the inheritance of resistance to metalaxyl in Phytophthora infestans. Plant Pathol. 37:4-11.

29. Tucker, C. M. 1931. Taxonomy of the Genus Phytophthora De Bary. University of Missouri, Columbia.

30. Wade, M. 1988. Strategies for preventing or delaying the onset of resistance to fungicides and for managing resistance occurrences. Pages 1415 in: Fungicide Resistance in North America. J. Delp, ed. The American Phytopathological Society, St. Paul, MN.

31. Yoshikawa, M., Tsukadaira, T., Masago, H., and Minoura, S. 1977. A nonpectolytic protein from Phytophthora capsici that macerates plant tissue. Physiol. Plant Pathol. 11:61-70. 